\section{俩 Heighten Science \\ P U B L I C I T I O N S Corporation ISSN 2573-6264}

\title{
Physical benefits of (Salah) prayer - Strengthen the faith \& fitness
}

\author{
Ghazal Kamran* \\ Senior Physiotherapist, Rehabilitation and Physical Medicine Institute, Al Ain Hospital, UAE
}

\section{Abstract}

The Physical benefits of Islamic prayer on the human body are discussed in this article. The act of prayer requires the worshiper to move through several distinct bodily postures while reciting a specific supplication. Salah involves a certain level of physical activity which includes standing, bowing prostration and sitting consecutively. Each position involves the movement of different parts of the human body in ways that Some muscles contract isometrically (same length) and some contract in approximation or isotonically (same tension). The prayer movements would enhance flexibility and general muscular fitness. This results in moderate physical exercise particularly to the large muscle group and encourage health and wellbeing. Besides being an excellent form of exercise, physical activity breaks the monotony of chores.

\section{Introduction}

Salah (Arabic term for Muslim Ritual/Islamic prayer) is a spiritual practice performed by Muslim believers which must be performed at least five times a day. There is a lot of discussion on the spiritual significance of Salah. The physical significance, however, is often overlooked. This article look into the way Muslims pray. The knowledge acquire through this article would help the health/fitness professional to explore the significance of the Prayer positions and may facilitate them to prescribe an individualized tailored exercise program for the Muslim population with special medical considerations. Anyone who does not perform prayer (non-muslims) can adopt these easy postures. For easy assimilation, comparison has been drawn from Yogic exercise postures as well.

\section{Description}

\section{Rakah during salah}

As an activity of Daily living, salah (prayer) is performed by Muslim believers at least 5 times a day; each prayer comprising of a certain number of repetitive units called Rak'ah [1]. A practicing Muslim if he offers FARD (Compulsory) Salah alone, repeats these Rak'ah a minimum of 17 times every day. The number of total Rak'ah is approximately 48 Raka'a per day which includes all mandatory and Optional Rak'ah. Table 1 summarizes the each daily prayer and different number of obligatory Rak'ah.

\section{Salah postures}

Prayers are comprised of several movements and postures. They include a certain number of Rak'ah, each Rak'ah consisting of a series of 7-9 postures.

The series of postures is fixed, and repeated a number of times for each act of prayer.

For example, before sunrise, two Rak'ah comprising a total of 14 postures must be performed. Thus, each Muslim is under obligation to perform 119 postures per day. 


\begin{tabular}{|c|c|c|c|c|c|c|c|}
\hline $\begin{array}{c}\text { SALAH and Pray } \\
\text { time }\end{array}$ & $\begin{array}{l}\text { SUNNAH } \\
\text { (Act by } \\
\text { Prophet) }\end{array}$ & $\begin{array}{c}\text { FARD } \\
\text { (Compulsory) }\end{array}$ & $\begin{array}{l}\text { SUNNAH } \\
\text { (Act by } \\
\text { Prophet) }\end{array}$ & $\begin{array}{c}\text { NAFL } \\
\text { (optional) }\end{array}$ & $\begin{array}{c}\text { WITR } \\
\text { (Odd Rak'ah, the last } \\
\text { prayer of night) }\end{array}$ & $\begin{array}{c}\text { NAFL } \\
\text { (optional) }\end{array}$ & $\begin{array}{l}\text { TOTAL } \\
\text { RAK AK } \\
\text { ?????? }\end{array}$ \\
\hline $\begin{array}{c}\text { FAJR } \\
\text { The dawn prayer }\end{array}$ & 2 & 2 & - & - & - & - & 4 \\
\hline $\begin{array}{l}\text { ZOHR } \\
\text { The afternoon } \\
\text { prayer }\end{array}$ & 4 & 4 & 2 & 2 & & - & 12 \\
\hline $\begin{array}{c}\text { ASR } \\
\text { The Late } \\
\text { Afternoon Prayer }\end{array}$ & 4 & 4 & - & - & - & - & 8 \\
\hline $\begin{array}{l}\text { MAGRIB } \\
\text { The evening } \\
\text { Prayer }\end{array}$ & - & 3 & 2 & 2 & - & - & 7 \\
\hline $\begin{array}{c}\text { ISHA } \\
\text { The Night Prayer }\end{array}$ & 4 & 4 & 2 & 2 & 3 & 2 & 17 \\
\hline
\end{tabular}

That is 3750 postures per month and a total of 42,840 postures per year. If a person lives up to an average of 50 years, Salah being obligatory from the age of 10 years, he would have performed approx. 1,713,600 compulsorily postures in his lifetime [2]. It is documented that a person may be expected to pray from the age of seven, five times a day; resulting in a significant number of knee and hip flexion over a lifetime an estimate of 70 times a day.

\section{Energy expenditure}

The duration of Salah may vary, depending upon individuals. Most Muslims can

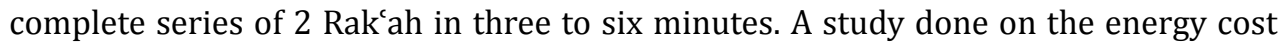
of two and four Rak'ah prayers in 32 male and female adults, found that Salah has a positive effect on metabolic function. For an $80 \mathrm{~kg}$ person, the energy cost of daily prayers was about 80 calories per day, and could be considered a form of physical activity that enhances fitness [3].

\section{Postures during prayers}

The person performing prayer recites Quran verses during different postures.

Takbir (standing) - Posture 1: Salah starts with standing posture called Takbir; At the Beginning the individual raises his hands to the level of his ears See figure 1.

Duration approximate 3 to $5 \mathrm{sec}$.

Qayyam (standing) - Posture 2: Lowering of the hands to the waist, shoulders relaxed, encouraging relaxed breathing. Upon standing the body weight is evenly distributed on both feet between the calcaneus and the distal end of the metatarsal bones See figure 2 .

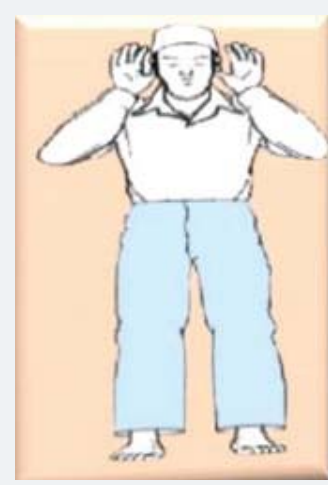

Figure 1: Takbir 


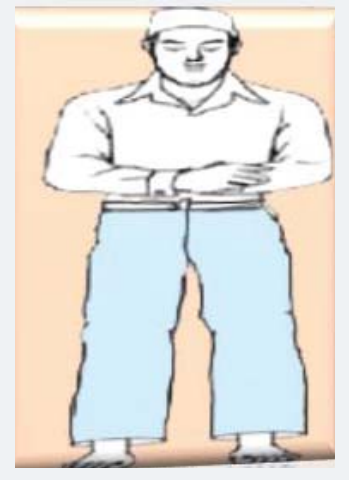

Figure 2: Qayyam

Duration approximate 40 to $60 \mathrm{sec}$.

Ruku (bowing) - Posture 3: Bowing with hands rested on the knees and the back held straight for a few seconds followed by the person rising back to an erect posture See figure 3 .

Duration 10 to $12 \mathrm{sec}$

Qayyam (standing) - Posture 4: After (Bowing) forward bending and returning to standing position See figure 4 .

Duration 5 to $6 \mathrm{sec}$

Sajdah (prostration) - Posture 5: The individual goes down on his/her knees and rests his/her hands and forehead on the ground in prostration known as Sajdah or Sujud. Seven body parts remain in contact with the floor See figure 5.

Duration 10 to $12 \mathrm{sec}$.

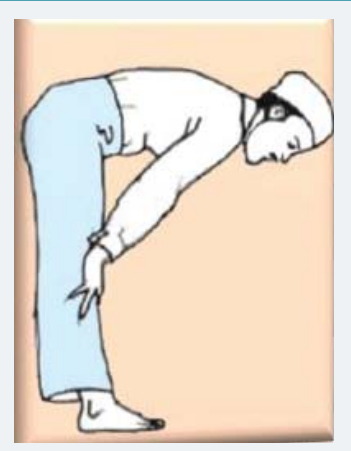

Figure 3: Ruk'u.

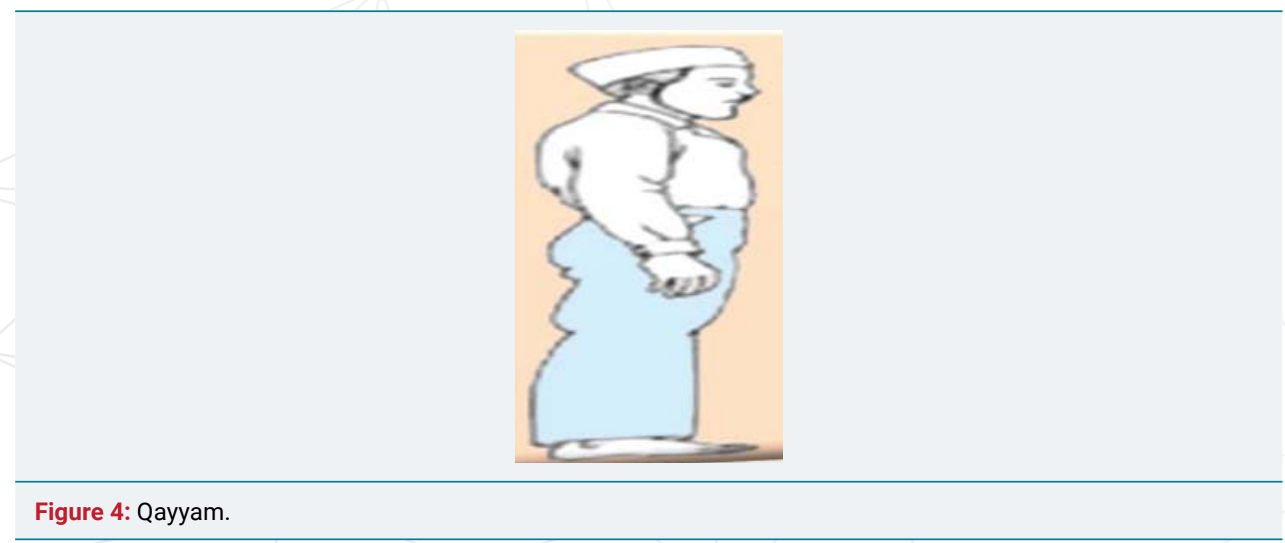


Jalsa/Tashahhud (sitting) - Posture 6: Muscles at the front of the ankle and foot are stretched, with toes extended and the knees and hip flexed. The lower back's good posture will help to strengthen the core muscles See figure 6.

Duration 6 to 8 Sec.

Sajdah (prostration) - Posture 7: Repetition of the deep prostration within a few seconds See figure 5.

Jalsa (sitting) - Posture 8 : The patient is sitting on floor in kneeling position for a little longer before the end of prayer See figure 7.

Duration: 40 to $60 \mathrm{sec}$

Salam: Posture - 9: Salah ends with turning the head to each side (right and left) See figures 8,9 .

Duration 3 to 4 sec.
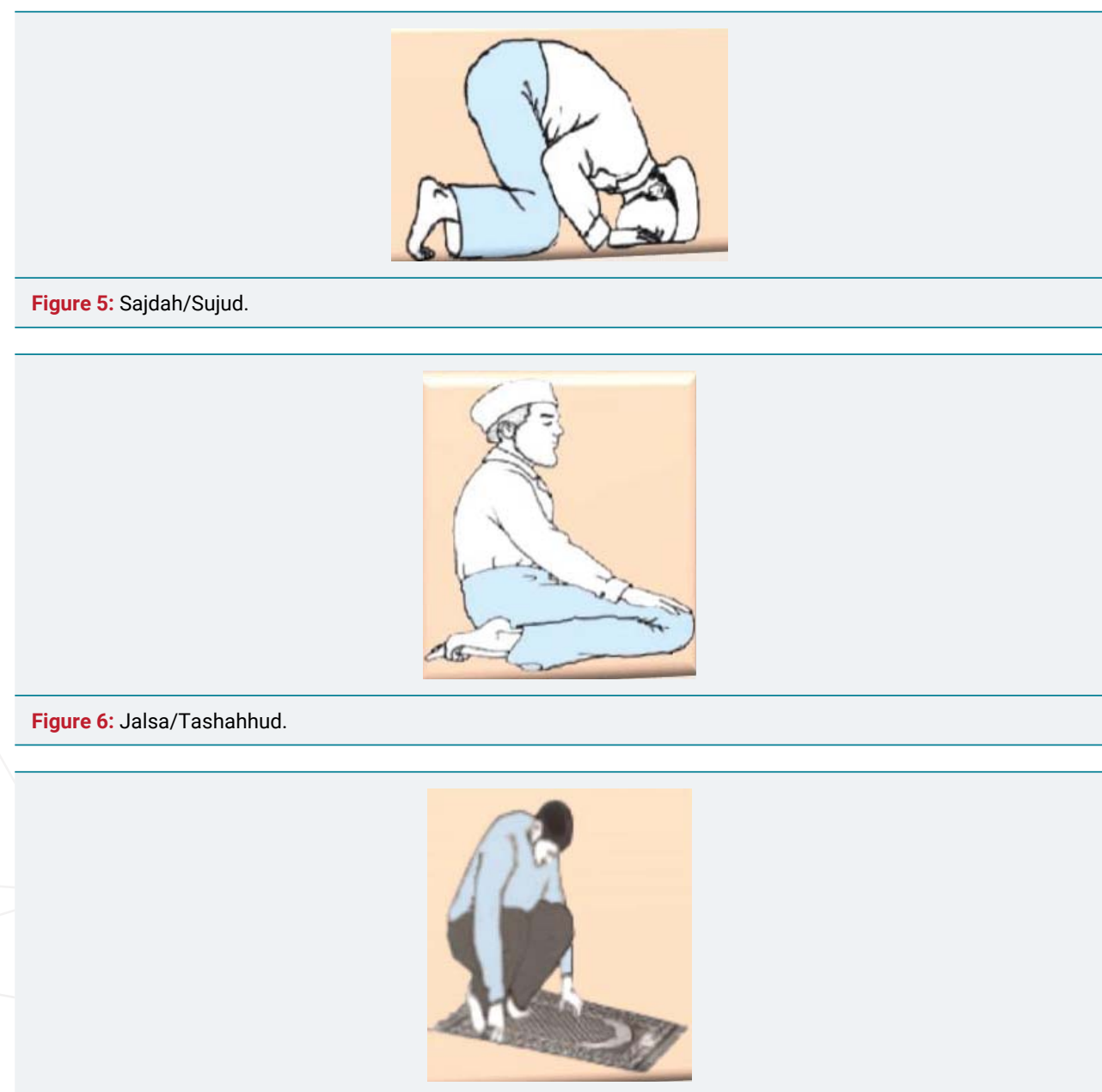

Figure 7: Rising up after Jalsa.

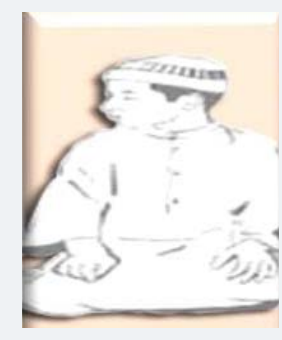

Figure 8: Salam to right 


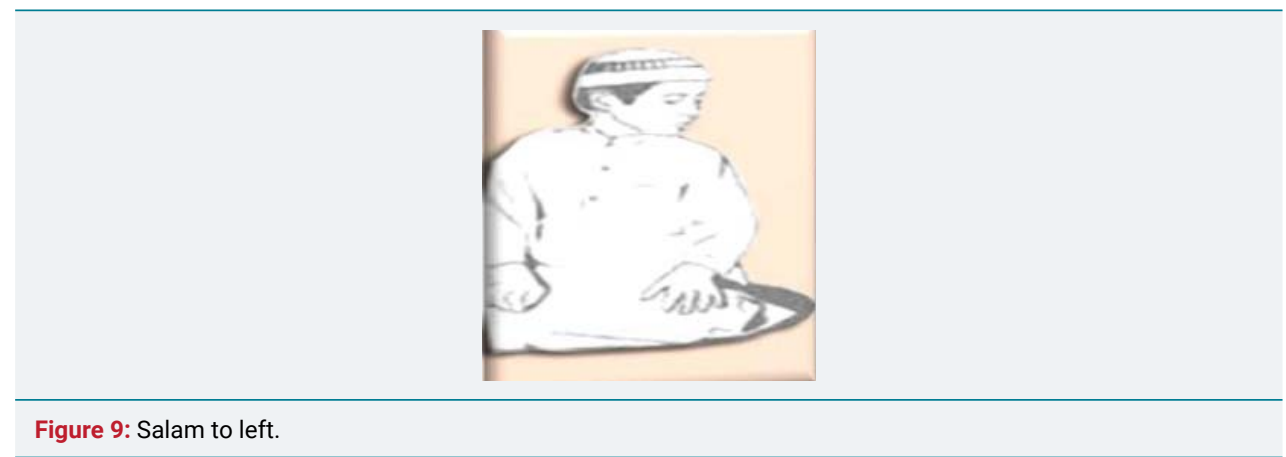

\section{Health significance of prayer postures}

Salah involves continuous gentle muscle contraction and relaxation with perfect harmony and balance. It involves different types of stretching and isometric contraction exercises. These gentle \& simple exercises are suitable for all ages \& conditions. University of Malaya Medical Centre (UMMC) Cardiology Consultant Specialist Prof Dr Wan Azman Wan Ahmad stated that " 12 'Rak'ah' (unit for a set of actions in a prayer) equaled to 30 minutes of light exercises daily as recommended by health experts." (zurairifm.wordpress.com/2009). Other beneficial activities can be combined with prayer, such as walking to the local mosque. This can help patients achieve the recommended weekly exercise levels of 30 minutes a day, at least five times a week. (Department of Health, 2004). For Muslim populations, higher ROM is required as their religious activities demands greater flexion of the joints in the lower limbs. Muslims need to adopt several postures that require deep flexion of the knee and hip to perform this daily obligation. The various postures of Salah were studied. Range of motion (ROM) were measured by Goniometer (An instrument which measures the available range of motion at a joint) [4].

\section{Prayer's posture health benefits}

Takbir \& Qayyam: Health benefits

Takbir is the beginning of the prayer and starts by raising the hands, keeping the palms open next to both ears, placing the thumbs behind the earlobes, keeping the elbows bent, the Pectoralis muscles stretched gently and the shoulder blades. Raising both hands and placing them on the stomach can expand the chest cavity [5] See Figure 1.

There is an even distribution of weight through both feet throughout the practice of Qayyam posture. This will ease the balance of the body and lower back brought into a neutral position whilst activating the core muscles at the same time. This position aids to straighten the back and improves posture [6] See figures 2,4.

Ibrahim and Siti, (2012) describes that three postures in Salah have been investigated and compared to similar stretching exercises, which were Takbir, bowing and prostration. This suggest that Salah has musculoskeletal effect like stretching [7].

Ruk'u/forward bending: Health benefits

Ruk'u is forward flexion of lumbar spine and flexion at hip joint whereas, knee joint bears load in extension. The American College of Sports Medicine (ACSM) recommends loading exercises (for example weight bearing in Ruk'u) to maintain bone health [8] which helps in minimizing the risk of Osteoporosis [9]. This position stretches the para spinal muscles of lumbar spine, hamstrings, and calves (gastrocnemius \& soleus) muscles See figure 3. It strengthens the back, extends the spine and increases the flexibility of hips and hamstrings. It relieve the stiffness at spine, neck, and back and help to improves posture as well as balance and co-ordination. Ruk'u is good for the lower vertebral column, trunk stability and provides a gentle distraction at vertebras. 
This posture is useful to treat backache and vertebral column related diseases [10]. It reduces the risk of nerve compression and promotes the flexibility of the spine in healthy people [11].

According to industrial engineering Prof. Muhammad Khasawneh et al, the complex physical movements of the ritual can reduce lower-back pain if performed regularly and properly. He and his interfaith team published their findings in the International Journal of Industrial and Systems Engineering. The maximum compression forces created during prayer postures are much lower than the safety limits set by the US National Institute for Occupational Safety and Health, and the movements can be safely considered a clinical treatment for lower-back pain [12]. In some cases of chronic low back pain, as part of exercise plan, I often advise my Muslim patient to prolong the Ruku'u position every time they Pray for a few more seconds in order get the effective sustain stretch.

Modifications to the bowing posture were studies for individuals with low back pain considering three main factors: back angle, knee angle, and pain level. It was found that all the main factors and one interaction effect (back angle $\times$ knee angle) are significant. This can help identify the back and knee angles that minimize the compression force for individuals with low back pain [12]. A Study (a research project carried out by University Malaya's biomedical engineering department) conducted on patients with regular back pain and pregnant mothers from the Malay, Indian and Chinese communities showed that the 'rukuk' and 'prostration' positions could be used as therapy as it helped to relax the spinal canal and reduced the risk of pressure on the spinal nerve. NOTE :The Non-Muslim mothers only acted out the positions during therapy sessions. (they showed the improvement within the month) [13].

\section{Jalsa/Tashahhud/Sitting: Health benefits}

Jalsa involves sitting on the floor directly on the ground, while both legs are folded in such a manner that the heels touch the gluteal region and the hands are placed on the knees. See figure 6 . In this pose muscles at the front of the ankle and foot are stretched. It stretches the tibalis anterior, the extensor hallucis longus (with toe extended), the quads and gluteus muscles (while knees and hips are flexed).

The full inner range of motion on knee joint is achieved and it prevents restricted joint range which is most commonly seen in patients with degenerative knee problems. The knee joint is noted to attain maximum flexion during the sitting posture, which was higher compared to the passive knee ROM [4]. Sitting with lower back in good posture will help to strengthen core muscles. Core strengthening has a strong theoretical basis in treatment and prevention of LBP [12]. Jalsa sitting in kneeling position - not only helps to maintain the good posture but also improves flexibility, and strengthens ligament [14].

Rising up after Jalsa to continue other Rak'ah involves activities like deep squats as well as full to half kneeling postures. With erect postures more spinal stability is gained [15] See Figure 7.

All these physical activities are therapeutic and merged with a variety of techniques prescribed by physical therapists, can be used to treat joint/muscle injuries and core coordination and balance reeducation.

\section{Sajdah/Sujud/Prostration: Health benefits}

The position of maintaining the lower back flexed and forehead resting gently on the floor allows the postural neck muscles to be activated in order to control the neutral head position in lowering down, and while lifting it from the floor. The hands are also stretched out in a manner that allows the forearm as well as the arm muscles 
to bear weight. Figure 5. The toes, entire vertebral column and upper and lower spinal muscle experiences a stretch. The knees forming a right angle allow abdominal muscles contraction to be activated and prevents flabbiness [2].

The hip joint was in maximum flexion during the prostration posture, which was much lower than the measured passive ROM [4]. The stretch felt in the length of spine as the individual curls the torso over the legs also creates a space between the dorsal surfaces of the vertebra of the spine and aids spinal distraction as well as allowing neural glides and the lengthening of the nerves [16]. This posture combined with other exercises opens the lower lumbar facet joints may help to reduce the lower back pain and sciatica can be used to treat spinal stenosis and other degenerative disc diseases [17].

Al-Gazal (2006) and Ayad (2008) stated that prostration is the only position in which the head is in a position lower than the heart and therefore, receives increased blood supply to the brain, stimulates the brain's frontal cortex. This reduces the chances of brain hemorrhage and headache, helps to reduces high blood pressure [2], This surge in blood supply also has a positive effect on memory, concentration, psyche and other cognitive abilities. A study investigating the alpha brain activity during prostration has reported increased amplitude in the parietal and occipital regions suggestive of parasympathetic elevation, thus indicating a state of relaxation (Doufesh,2012) [18].

Salaam/Neck Turns: Health benefits

Salam is an excellent form of neck and upper vertebrae exercise. The head performs rotational movements over the cervical vertebra. This improves the range of motion of the neck and whilst stretching the trapezius fibers. It also helps to mobilize the upper back and the thoracic muscles. These gentle neural stretches at cervical rotation are effective and may reduce the symptoms of cervicogenic headache [19] Figures 8,9.

Al- Gazal and Ayad et al. (2008) stated that the neck muscles, in particular, are strengthened such that it is uncommon to find a person offering regular Salah prostrating at least 40 times a day to suffer from cervical spondylosis or myalgias.

\section{Salah \& yoga}

This is suggested that, salah movements can be another alternative to the existing exercises, like yoga and pilates. Salah has become an integral part of Muslims daily activities since the seventh century and whilst salah is performed as a religious obligation, it is suggested that salah postures can simultaneously give all the benefits of yoga. Salah postures are similar to some yoga postures [1]. An attempt is made below to discuss semblance in yoga $\&$ salah posture.

In salah, a Muslim is required to focus during prayers and leave out all life distractions and connect with Allah during that time.

During meditation in yoga the mind is clear, relaxed, and inwardly focused, the individual is fully awake and alert, but the mind is not focused on the external world or on the events taking place around the individual [2] See Figure 10.

Qayyam/Takbir (the start of Salah with standing straight with the hands placed on the abdomen). This standing posture is similar to Namaste in yoga. The word itself means "Bow me you" or "I bow to you," Yogis place the hands together at the heart chakra to increase the flow of the divine love, bowing the head and closing the eyes. See figures $2 \& 10$.

Ruku' is the forward bending position in Muslim's prayers. It is a humbling act of bowing down to Allah, letting go of one's pride and submitting to Allah. Similarly in yoga Ardha Uttansana fully stretches the muscles of the lower back, front torso, thighs, and calves See figures 3,10. 
Sajdah, where the forehead touches the ground. It is mentioned in a Hadith that this is the position where Muslims are most near to his Creator. Abu Huraira reported that the messenger of Allah said: "The nearest a servant comes to his Lord is when he is prostrating himself, so make supplication (in this state)" [Sahih Muslim, Book of Prayer, Hadith: 482]. The pose called Balasana (Child pose) in yoga is the like Sajdah pose. The muscle work and stretches in these poses help in releasing the pain/tension in the lower back, shoulders and chest [20] See figures 5,10.

Julus: sitting on floor Where a Muslim recites the in the second and last Rakka of the prayer is quite like Vajrasana. This is the term used by yogis to describe that same pose. This position helps in getting rid of constipation, fighting stomach disorders, and improving the body blood circulation [21]. It also helps in calming the mind and stimulates the body to relax. See figures 6,10 .

\section{What if I can't pray in these positions due to my pain?}

Islam allows flexibility in the positions of prayer during illness.

As Prophet Muhammad (Peace Be Upon Him) said, "Pray while standing and if you can't, pray while sitting and if you cannot do even that, then pray lying on your side". (Al-Bukhari 2:20, 218). See Figures 11-13.

A person with knee pain can use prayer rug or kneeling pad which gives extra support to pray on floor.

\section{Physical fitness, physıotherapy and salah}

Among the important activities of daily living in Muslim populations is the act of prayer. It is crucial for every Muslim to be able to perform these various postures, which require significant amount of flexion of the lower limb joints to fulfil their religious responsibilities. As these postures demand greater Range Of Motion (ROM), It is among the major concerns for Muslim patients indicated for total knee or hip arthroplasty [4].
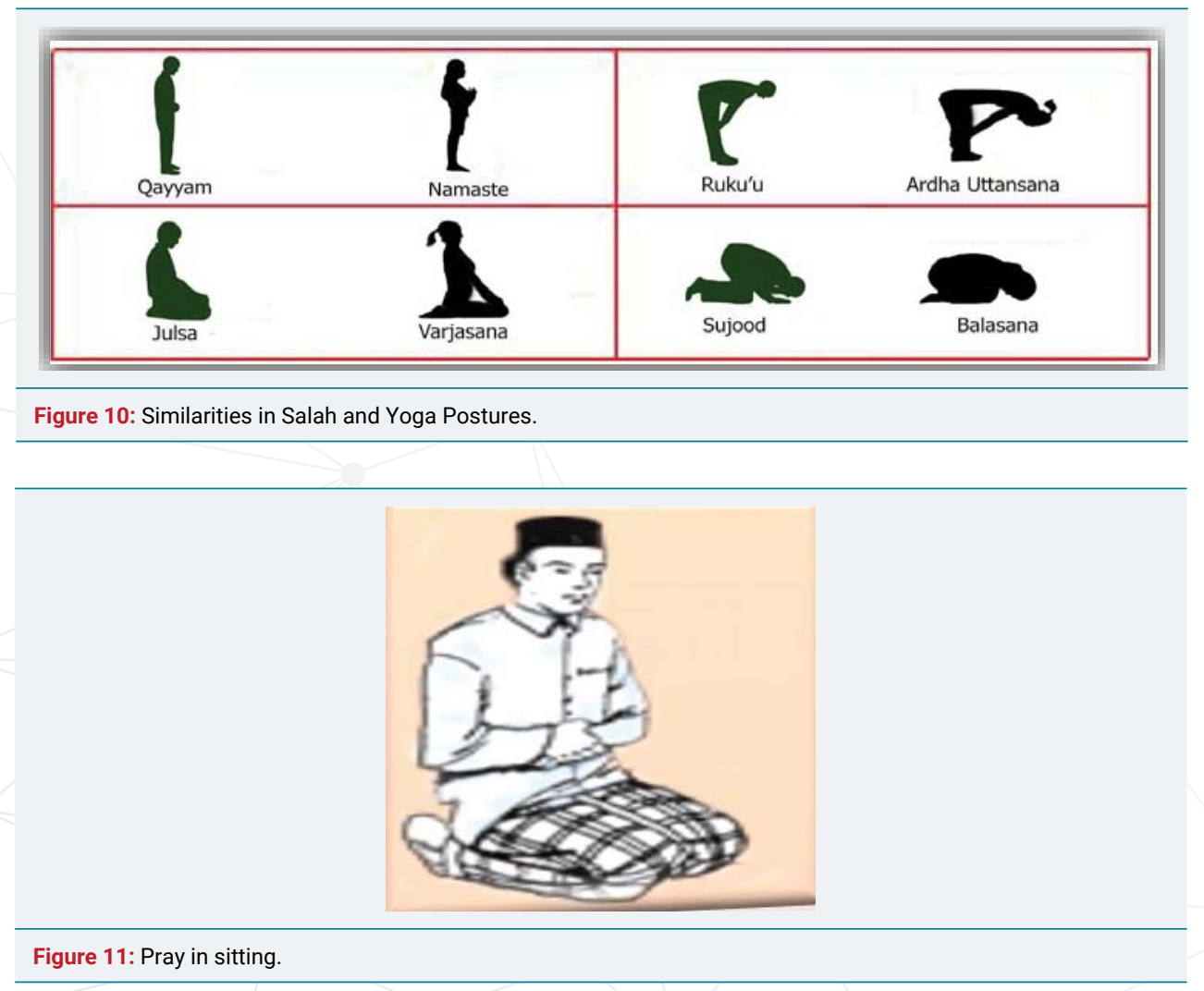


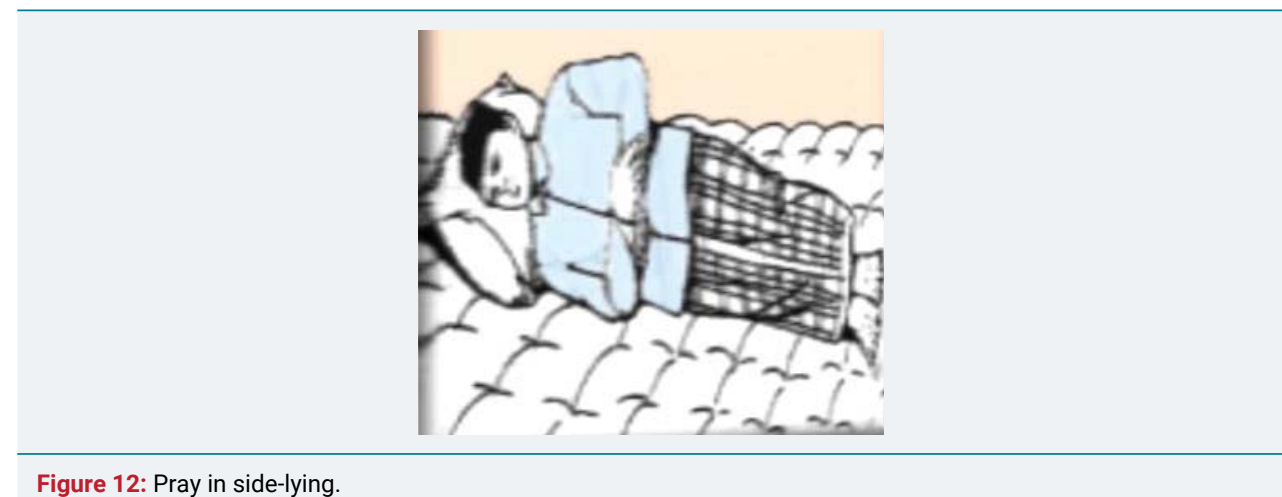

Figure 12: Pray in side-lying.

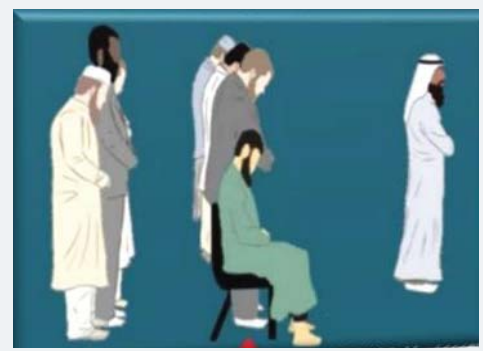

Figure 13: Praying on chair.

Based on a study [4], The current available replacement device needs the range required to conduct Muslim prayers adequately for the hip joint. However, the available knee implant device does not yet allow Muslim individuals to satisfy their daily act of prayer.

The recent research [22-24], conducted considering four main factors: population, gender, percentile, and prayer posture. For healthy individuals, the results showed that there is an inverse relationship between the time spent on each prayer posture and the back compression force affecting the person during that posture. In addition, modifications to the bowing posture were studies for individuals with low back pain considering three main factors: back angle, knee angle, and pain level. It was found that all the main factors and one interaction effect (back angle $\times$ knee angle) are significant. This can help identify the back and knee angles that minimize the compression force for individuals with low back pain.

Physical rehabilitation involves doing a regular, gentle stretch and strengthen movement program. Regular movement involves in Salah will help to decrease the stiffness in joints and lower limb stretches prevent muscle injuries [9]. It also increases the strength of the muscles, in order to improve physical fitness. This is necessary to be able to return to activities such as, cooking, housework, prayers (Salah) and work.

In the acute injury phase/acute medical conditions or in the early post-surgical stage, patient can pray in modified positions, but as soon as the inflammatory process subsides and the recovery starts, the Fitness expert in clinical setting can develop an exercise training program and set rehabilitative goals tailored for an individual to improve joint flexibility and to strengthen the muscle groups involved in standing, forwarding bending, kneeling, squatting and prostrating, thereby encouraging the patient to return to the normal praying position gradually.

The knee joint is highly loaded during daily life. If each posture has been performed correctly then the individual may prevent knee problems. But many Muslims today aren't aware of the proper postures. Some pray at a very fast pace, this way they are harming their knees, even when standing sometimes they put pressure on one foot more than the other, overload can lead to more joint problems. Some do not bend at 
right angle in Ruku posture therefore doesn't get proper spinal flexibility and lower extremity stretch. It's being observed also that many people continued to pray on chair even after the acute or sub-acute phase subsided and the consequence are muscle shortening and joint stiffness at knee \& hip and tightness at ligaments and tendons, eventually their physical fitness level is compromised.

Movement in prayer if done in the proper position can prevent, treat and rehabilitate a number of diseases. If prayer is practiced to perfection, this practice may nourish the heart, strengthen the kidney, treat impotence for men, improve the quality of sex and genital muscle recovery (neurotherapy-of-christian-brain, 2014) [13].

A'ishah Siddiqa (Wife of Prophet, PBUH) narrates that The Prophet used to prolong the prostration to such an extent that one could recite fifty verses (of the Qur'an) before he would lift his head [Sahih al-Bukhari] In another Hadith narrated by Anas bin Malik (radiAllahu anhu) the Prophet (PBUH) advised Muslims to perform Ruku'u (bowing) and Sajdah properly.

\section{Conclusion}

Prayer movements outside of worship, have many physical \& physiological advantages. The body goes through a unique exercise routine during the Salah therefore these postures help to maintain fitness in the healthy individuals [6], leading to improved flexibility, muscle strength (ability of muscle to exert force) and muscle endurance (refers to the ability to perform many repetition) [8].

Over the years many have suggested that the Islamic prayer contains benefits associated with yoga and however it would be more correct to say that these health regimes incorporate many of the health benefits contained in the prayer [2].

If performed properly and regularly, the praying postures can also be very useful to aid rehabilitation in a variety of conditions. As part of spiritual act, the doers also perform slow and moderate exercise at the same time which could benefit their health.

Public health awareness is crucial in order to gain maximum physical health benefit associated with Prayer Postures among the Muslim population. Further studies are required to help the healthcare providers to formulate an effective exercise program for patients with medical considerations that may interfere with prayer posture.

\section{References}

1. Sayeed SA, Prakash A. Islamic prayer (Salah/Namaz) and yoga togetherness in mental health. Indian J Psychiatry. 2013; 55: 224-230. Ref.: https://goo.gl/R6ZcgF

2. Imamoglu O, Dilek AN. Common Benefits of Prayer and Yoga on Human Organism. Int J Sci Culture Sport. 2016; 2148-1148. Ref.: https://goo.gl/YiR8zR

3. Jasem Ramadan Alkandar. Bioenergetics of Islamic Prayers, measuring the amount of oxygen and calories the physical movements of the prayers burned. National Task Force Chairperson. Kuwait.

4. Sharifudin MA, Arshad AA, Johari MH, Rahman NA. The Study on Range of Motion of Hip And Knee in Prayer by Adult Muslim Males. A Preliminary Report. Int Medical J Malaysia. 2015; 14: 49-58. Ref.: https://goo.gl/LkZTeZ

5. Elaine Paulinl, Antonio Fernando Brunettoll, Celso Ricardo Fernandes Carvalho. Effects of a physical exercise program designed to increase thoracic expansion in chronic obstructive pulmonary disease patients. Pneumologia J. 2003; 29: 5. Ref.: https://goo.gl/mUfvL6

6. Winter DA. Human balance and posture control during standing and walking. Department of Kinesiology, University of Waterloo, Waterloo, Ontario, Canada. 1995; 3: 193-214. Ref.: https://goo.gl/ib4PtY

7. Rockville MD. Office of the Surgeon General (US). Bone Health and Osteoporosis: A Report of the Surgeon General. US department of Health and Human Services. 2004. Ref.: https://goo.gl/MXeUMP

8. Pescatello LS, Arena R, Riebe D, Thompson PD, Kluwer W, et al. ACSM 's Guidelines for exercises Testing and Prescription. J Canadian Chiropractic Association. 2014; 58: 328. Ref.: https://goo.gl/UE9aWz 
9. Pope RP, Herbert RD, Kirwan JD, Graham BJ. A randomized trial of pre exercise stretching for prevention of lower-limb injury. Med Sci Sports Exerc. 2000; 32: 271-277. Ref.: https://goo.gl/6zT6tf

10. Snook SH, Webster BS, McGorry RW, Fogleman MT, McCann KB. The reduction of chronic nonspecific low back pain through the control of early morning lumbar flexion: a randomized controlled trial. Spine (Phila Pa 1976). 1998; 23: 2601-2607. Ref.: https://goo.gl/9Zu4E2

11. Whitman JM, Flynn TW, Childs JD, Wainner RS, Gill HE, et al. A comparison between two physical therapy treatment programs for patients with lumbar spinal stenosis: a randomized clinical trial. Spine (Phila Pa 1976). 2006; 31: 2541-2549. Ref.: https://goo.gl/Tq3YW6

12. Akuthota V, Ferreiro A, Moore T, Fredericson M. Core stability exercise principles. Curr Sports Med Rep. 2008; 7: 39-44. Ref.: https://goo.gl/X2P8CK

13. Dogu Y. Benefit of Prayers as Physical Activity. Int J Science Culture Sport. 2016; 4: 306-318. Ref.: https://goo.gl/4tKLbG

14. MacGregor H. Moving and Handling Patients at a Glance. London UK-Edition Published Page. 2016; 123. Ref.: https://goo.gl/Fr7Rkf

15. Lawrence M. The Complete Guide to Core Stability. 2013; 2. Ref.: https://goo.gl/Zwwp5u

16. Shacklock M. Clinical Neurodynamics: A New System of Musculoskeletal Treatment. Elsevier Health Science. 2005; 2. Ref.: https://goo.gl/rj5ZB7

17. Ji B, Sorensen R, Friis A, Nygaard O, Indahl A, et al. Randomized clinical trial of lumbar instrumented fusion and cognitive intervention and exercises in patients with chronic low back pain and disc degeneration. Spine (Phila Pa 1976). 2003; 28: 1913-1921. Ref.: https://goo.gl/oYRFKx

18. Ahmed SA, Ibrahim F. Investigation of Electromyographic Activity during Namaz and Stretching Exercise. International Conference on Biomedical Engineering and Sciences. 2012. Ref.: https://goo.gl/K8rw8k

19. Jull G, Trott P, Potter H, Zito G, Niere K, et al. A Randomized Controlled Trial of Exercise and Manipulative Therapy for Cervicogenic Headache. Spine (Phila Pa 1976). 2002; 27: 1835-1843. Ref.: https://goo.gl/KfpMFo

20. Cramer $\mathrm{H}$, Lauche $\mathrm{R}$, Haller $\mathrm{H}$, Dobos $\mathrm{G}$. A systematic review and meta-analysis of yoga for low back pain. Clin J Pain. 2013; 29: 450-460. Ref.: https://goo.gl/w4w8AL

21. Bhavanani AB. Principles and methods of yoga therapy. South India. 2007. Ref.: https://goo.gl/M5dPt4

22. Aqlan F, Ahmed A, Cao W, Khasawneh MT. An ergonomic study of body motions during Muslim prayer using digital human modelling. Int. J Industrial \& Systems Engineering. 2017; 25. Ref.: https://goo.gl/qWnfyw

23. Ghorbani A, SA Moosavi. The Effect of Prostration (Sajda) on Cerebral Blood Flow Velocity. J Rafsanjan Univ Med Sci. 2007; 6: 49-54. Ref.: https://goo.gl/UWX5YH

24. Salleh NA, Lim KS, Ibrahim F. AR Modelling as EEG Spectral Analysis on Prostration, Proceedings of International Conference for Technical Postgraduates. 2009. Ref.: https://goo.gl/eAU6X2 